\title{
Proton precipitation during transpolar auroral events: Observations with the IMAGE-FUV imagers
}

\author{
B. Hubert, ${ }^{1}$ J. C. Gérard, ${ }^{1}$ S. A. Fuselier, ${ }^{2}$ S. B. Mende, ${ }^{3}$ and J. L. Burch ${ }^{4}$ \\ Received 14 July 2003; revised 15 March 2004; accepted 26 March 2004; published 10 June 2004.
}

[1] Several transpolar auroras have been observed with the IMAGE-Far Ultraviolet (FUV) imagers. The unique capability of the IMAGE-FUV experiment to image the proton and electron aurora simultaneously on a global scale is used to study this phenomenon. A set of 12 transpolar aurora observed with IMAGE-FUV is studied. We find that the dynamics of the transpolar aurora in relation with the IMF is consistent with previously published studies. The proton energy flux in the transpolar structure is determined and compared with the electron contribution. The contribution of the proton aurora inside the transpolar arc is also considered at the global scale. On the average, transpolar structure contributes $\sim 10 \%$ of the total precipitation. We find that the proton precipitation carries $\sim 5 \%$ of the energy flux of the transpolar arc. In 11 of the 12 cases of transpolar events studied, a local brightening of the auroral Lyman- $\alpha$ emission is detected concurrently with the appearance of the transpolar structure. The intensification takes place at the nightside base of the transpolar arc, in the auroral oval. The duration of the intensification is variable but shorter than the lifetime of the transpolar arc. This study also suggests that the localized intensification is mainly due to an increase of the proton precipitation. INDEX TERMS: 2455 Ionosphere: Particle precipitation; 2704 Magnetospheric Physics: Auroral phenomena (2407); 2776 Magnetospheric Physics: Polar cap phenomena; 7847 Space Plasma Physics: Radiation processes; KEYWORDS: transpolar aurora, proton aurora, auroral remote sensing

Citation: Hubert, B., J. C. Gérard, S. A. Fuselier, S. B. Mende, and J. L. Burch (2004), Proton precipitation during transpolar auroral events: Observations with the IMAGE-FUV imagers, J. Geophys. Res., 109, A06204, doi:10.1029/2003JA010136.

\section{Introduction}

[2] The first global views of the transpolar aurora, i.e., a long-lived auroral structure extending across the polar region, were obtained by Frank et al. [1982, 1986] using the global imaging instrument onboard the Dynamics Explorer 1 spacecraft. These features are also referred to as theta aurora, because of their characteristic shape (we further refer indifferently to both terminologies). Since then, the interest for these particular structures has grown steadily both from the observational and theoretical points of view.

[3] The relationship between transpolar arcs and the solar wind IMF has been widely studied: Polar arcs appear during quiet periods of predominantly northward IMF [Frank and Craven, 1988; Valladares et al., 1994]. The location of the arcs is determined by the sign of IMF $B_{y}$ (here described for the Northern Hemisphere). Static arcs near the dawn (dusk) oval side are connected to dawnward (duskward) IMF [Valladares et al., 1994; Kullen et al., 2002]. Arcs that

\footnotetext{
${ }^{1}$ Laboratoire de Physique Atmosphérique et Planétaire, Institut d'Astrophysique et de Géophysique, Université de Liège, Liege, Belgium.

${ }^{2}$ Space Physics Laboratory, Lockheed Martin Advanced Technology Center, Palo Alto, California, USA.

${ }^{3}$ Space Sciences Laboratory, University of California, Berkeley, California, USA.

${ }^{4}$ Southwest Research Institute, San Antonio, Texas, USA.

Copyright 2004 by the American Geophysical Union. 0148-0227/04/2003JA010136\$09.00
}

move over (parts of) the polar cap are triggered by an IMF $B_{y}$ or $B_{z}$ sign change [Cumnock et al., 1997; Newell et al., 1997; Chang et al., 1998; Kullen et al., 2002]. The polar arc always moves toward the direction of IMF $B_{y}$ (dawnward motion for dawnward IMF $B_{y}$ and duskward motion for duskward IMF $B_{y}$ ): Kullen et al. [2002] found that a moving arc develops, with high solar wind IMF magnitude and velocity, in the dusk (dawn) sector when the IMF $B_{y}$ is duskward (dawnward), a $B_{y}$ change of sign to the dawn (dusk) side of the oval initiating the movement of the transpolar arc from dusk to dawn (dawn to dusk, respectively). These authors also found that midnight arcs occur at high solar wind speed with varying IMF $B_{y}$ and $B_{z}$ and at least one hour of predominantly northward IMF, at the end of a substorm recovery phase. Cumnock et al. [2002] found that no $B_{z}$ sign change is needed for theta aurora formation. As shown in the Cumnock et al. [1997] and Kullen et al. [2002] studies, for moving arcs, the large-scale IMF $B_{y}$ sign change takes place up to an hour before the arc appears, and the arc moves within 2-4 hours over the polar cap. It is also suggested that the IMF sign change causes a jump of the dayside merging line [Chang et al., 1998; Newell et al., 1997] and a large-scale tail reconfiguration (tail twist rotation) [Kullen, 2000; Slinker et al., 2001; Kullen and Janhunen, 2003] leading to a bifurcation of closed field lines in the tail and the polar cap. Several authors suggested that the convection cells on the night side magnetosphere are occasionally twisted and split into two parts, forming additional convection cells, the transpolar aurora reflecting 
the boundary between these cells [Frank et al., 1986; Chang et al., 1998, and references therein; Cumnock et al., 2002].

[4] The topology of the field lines in a theta aurora is another widely studied topic. Peterson and Shelley [1984] and Frank et al. [1986] explained that the field lines threading the transpolar arcs were closed through the plasma sheet or the plasma sheet boundary layer. Menietti and Burch [1987] used DE1 high-altitude plasma instrument (HAPI) electron and ion data and found that the theta aurora occurs on closed field lines with particle signatures and plasma parameters similar to those of the magnetospheric boundary plasma sheet. Frank and Craven [1988] showed that large-scale transpolar arcs lie on closed field lines. In their review, Zhu et al. [1997] considered that the open-closed field line issue of the transpolar arcs is still controversial. However, Meng and Mauk [1991] suggested that the controversy about the origin of particles in polar arcs probably appeared because different authors have studied different types of arcs, and that large-scale polar arcs probably lie on closed field lines while small-scale arcs lie on open field lines.

[5] Makita et al. [1991] used DMSP-F6 data and determined that, in transpolar arcs, precipitating electrons have a peak energy at about a few $\mathrm{keV}$, and protons have a high energy component above $10 \mathrm{keV}$. Cumnock et al. [2000, 2002] presented transpolar aurora particle measurements with ion fluxes ranging from a fraction of $\mathrm{mW} / \mathrm{m}^{2}$ up to $\sim 1 \mathrm{~mW} / \mathrm{m}^{2}$ and typical average energy of a few $\mathrm{keV}$, while the electron precipitation had a flux occasionally larger than $1 \mathrm{~mW} / \mathrm{m}^{2}$ and a typical average energy of $\sim 0.5 \mathrm{keV}$. In general, typical particle energies associated with transpolar arcs are slightly lower than in the main oval [Zhu et al., 1997].

[6] Murphree et al. [1987] reported a brightening of the auroral oval at the base of the transpolar arc. Their morphological study was based on UVI images of the Viking spacecraft, not allowing any study of the proton contribution to this auroral feature. These authors observed that the dynamics associated with the connection region is highly variable, and that the bright spot can either move with the connection between the arc and the oval, or move relative to it, and also that the development can be different for ovalaligned arc. These authors also raised the question of the connection between transpolar auroras and substorms, or pseudobreakups concerning the spot. Pseudobreakups [Akasofu, 1964] are short-lived auroral substorm-like events that do not grow to the strength of a substorm. Their properties are similar to those of substorm onsets. They can occur as substorm precursors [Koskinen et al., 1993], or isolated events during quiet times [Sergeev et al., 1986].

[7] The question of the proton contribution to the transpolar aurora could not be addressed on a global scale before the availability of global images of the proton aurora. Protons significantly contribute to the auroral energy input and protons and electrons do not necessarily react in the same way to potential injection mechanisms. It is thus of interest to compare proton and electron precipitations, in order to better understand the physics of auroral injection mechanisms. For example, electromagnetic ion cyclotron instabilities were proposed by S. Fuselier et al. [Generation of transient dayside sub-auroral proton precipitation, submitted to Journal of Geophysical Research, 2004] to explain the observation of dayside subauroral proton flashes [Hubert et al., 2003] because they can cause proton injection more efficiently than electron injections. The observation of both the electron and proton aurora thus enriches the understanding of the magnetospheric phenomena and their diversity.

[8] In this study, we focus on the proton precipitation during transpolar events in the theta arc itself, as well as in the main oval. In particular, we use observations performed with the SI12 imager on board the IMAGE spacecraft [Burch, 2000; Burch et al., 2001] that produces global images of the Doppler-shifted Lyman- $\alpha$ emission, which is solely excited by precipitating protons. We study the proton injection in spots observed at the connection between the transpolar arc and the oval. A limited pseudobreakup study will also be carried out in order to compare the spot properties with the pseudobreakup properties.

\section{IMAGE-FUV Imagers}

[9] The IMAGE satellite was launched on 25 March 2000 , into an eccentric orbit with an apogee of $\sim 7 R_{E}$ and a perigee of $\sim 1000 \mathrm{~km}$. Its orbital period is $\sim 14$ hours. The FUV experiment [Mende et al., 2000a, 2000b] includes three imagers: the Wide Band Imaging Camera (WIC) observes the $\mathrm{N}_{2} \mathrm{LBH}$ bands between 135 and $180 \mathrm{~nm}$, the first Spectrographic Imager (SI13) is centered on the OI $135.6 \mathrm{~nm}$ transition, and the second Spectrographic Imager at $121.8 \mathrm{~nm}$ (SI12) observes the Doppler-shifted Lyman- $\alpha$ emissions due to the proton aurora. The geocoronal Lyman- $\alpha$ component at rest wavelength is efficiently rejected by the instrument, as well as the nearby NI $120 \mathrm{~nm}$ line. The cameras are switched off when passing through the radiation belts and at specific periods to avoid direct sunlight exposure, so that images are taken $\sim 2 / 3$ of the time. The WIC and SI13 cameras image emissions mostly produced by the electron aurora. The additional contribution due to proton precipitation and the secondary electrons they generate can be removed on the basis of the SI12 measurements. The proton energy fluxes are obtained from the SI12 count rate using the relationship between the SI12 signal and NOAA in situ measurements of proton precipitation [Coumans et al., 2002]. The three images can be used to determine the average energy and energy flux of the auroral electron and the energy flux of the precipitated protons based on an assumption on the average energy of the auroral protons [Hubert et al., 2002; Meurant et al., 2003]. This energy can obtained from an empirical precipitation model [Hardy et al., 1989, 1991], but an $8 \mathrm{keV}$ assumption is made inside the transpolar arc: a reasonable value considering the results of Cumnock et al. [2002]. The snapshots taken simultaneously once every $2 \mathrm{~min}$ by the WIC, SI13 and SI12 imagers are well suited to a study of the dynamics, morphology and energetics of the global electron and proton precipitations during transpolar arc events.

[10] This study is based on 12 cases of transpolar auroras observed with IMAGE-FUV between November 2000 and February 2002 in the Northern Hemisphere. We concentrate on wintertime events because theta auroras are generally weak structures easily contaminated by dayglow. The only other bias introduced in this study is that the brighter and 
Table 1. List of Studied Events ${ }^{\mathrm{a}}$

\begin{tabular}{|c|c|c|c|c|c|}
\hline \multirow[b]{2}{*}{ Event } & \multirow{2}{*}{$\begin{array}{l}\text { Presence } \\
\text { of a Proton } \\
\text { Spot }^{\mathrm{a}}\end{array}$} & \multirow{2}{*}{$\begin{array}{l}\text { Approximate } \\
\text { Spot } \\
\text { Duration, }{ }^{b} \\
\text { min }\end{array}$} & \multicolumn{3}{|c|}{$\begin{array}{l}\text { IMF Component } \\
\text { Sign Reversal }^{\mathrm{c}}\end{array}$} \\
\hline & & & $B_{z}$ & $B y$ & $B_{x}$ \\
\hline 5 Nov. 2000 & yes & 70 & $\ldots$ & $\ldots$ & \\
\hline 8 Nov. $2000^{\mathrm{d}}$ & yes & 20 & & & \\
\hline 26 Nov. 2000 & yes & 60 & $\ldots$ & $\mathrm{X}$ & $\mathrm{X}$ \\
\hline 27 Nov. $2000^{d}$ & yes & $?^{\mathrm{e}}$ & & & \\
\hline 10 Jan. 2001 & no & & & & \\
\hline 25 Nov. 2001 & yes & $60 ; 50^{\mathrm{f}}$ & $\ldots$ & $\ldots$ & $\mathrm{X}$ \\
\hline 2 Dec. 2001 & yes & 210 & $\ldots$ & $\ldots$ & $\mathrm{X}$ \\
\hline 30 Dec. 2001 & yes & $?^{\mathrm{g}}$ & $\ldots$ & $\ldots$ & \\
\hline 19 Jan. 2002 & yes & 45 & 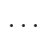 & $\ldots$ & $\mathrm{X}$ \\
\hline 5 Feb. $2002 \mathrm{a}$ & yes & $>30^{\mathrm{g}}$ & $\mathrm{X}$ & $\mathrm{X}$ & \\
\hline 5 Feb. 2002b & yes & $>90$ & & & \\
\hline 11 Feb. 2002 & yes & $?^{\mathrm{h}}$ & $\mathrm{X}$ & $\mathrm{X}$ & \\
\hline
\end{tabular}

${ }^{\mathrm{a}}$ Cases presenting a proton intensification on the nightside oval at the base of the transpolar arc

${ }^{\mathrm{b}}$ Approximate duration of the period of proton intensification.

${ }^{\mathrm{c}}$ Changes of sign of the IMF components that encountered at least one change of sign at (or closely prior to) the formation of the spot (X signifies yes and three dots signify no).

${ }^{\mathrm{d}}$ For events disturbed by an interplanetary shocks, an interplanetary magnetic field (IMF) analysis is not relevant.

eProton intensification not located at the base of the transpolar arc at the onset. Proton oval already active in the post-midnight (i.e., at the base of the transpolar arc) sector before the development of the transpolar aurora.

${ }^{\mathrm{f}}$ Two spots appear successively together with the formation of distorted transpolar arcs.

${ }^{\mathrm{g}}$ The spot extends and then appears as decoupled from the transpolar arc. ${ }^{\mathrm{h}}$ When the satellite is closer to the planet, the part of interest of the oval gets out of the field of view, so that the duration cannot be estimated in this case.

thicker transpolar auroras were selected for detection threshold reasons. Narrow transpolar auroras can be too faint to be efficiently detected from the IMAGE apogee altitude of $7 R_{E}$. The 12 studied events are listed in Table 1. Solar wind data were obtained with the ACE, Wind and Geotail satellites.

\section{Brightening of the Proton Auroral Oval 3.1. Observations}

[11] During several transpolar events, an increase of the auroral Lyman- $\alpha$ brightness was detected with the SI12 imager. The observed brightening generally takes place at the nightside foot of the transpolar arc, and can have a variable extension in magnetic local time (MLT), from a few minutes to several MLT hours. The brightening does not necessarily last for the whole period of time of the transpolar event. Figure 1 displays the raw counts (after removal of the background, and mapping in geomagnetic coordinates) obtained with WIC and SI12 at 0743, 0812 and 0814 UT on 5 November 2000. It shows the transpolar structure, which was present between 0500 and 0915 UT, and the appearance of the spot in the main oval. A period of positive IMF $B_{z}$ (Figure 2) favors the formation of transpolar structure, and the appearance in the dusk sector is consistent with the positive $B_{y}$ component of the IMF (Figure 2). In this study, the IMF components are expressed in GSM coordinates. Figure 3 shows the proton and electron energy fluxes calculated from the WIC, SI13 and SI12 images, revealing the proton spot observed at 0813 UT. The calculated energy fluxes in the transpolar arc are consistent with previous in situ measurements of Cumnock et al. $[2000,2002]$, i.e., on the order of $1 \mathrm{~mW} / \mathrm{m}^{2}$. The

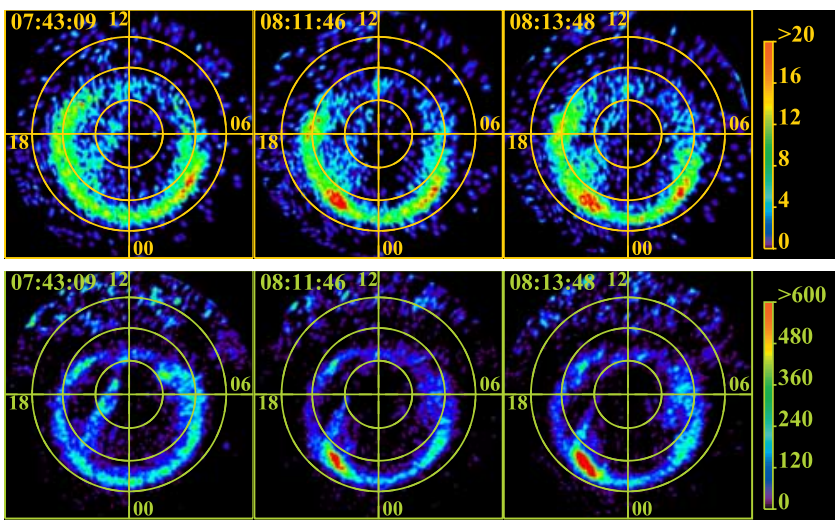

Figure 1. Observations of the (top) IMAGE-FUV SI12 and (bottom) WIC imagers obtained on 5 November 2000, presented in geomagnetic coordinates. The UT times are given in the upper left corner of each image: concentric circles are separated by $10^{\circ}$ MLAT. The color scale is expressed in counts; the count background has been removed. The transpolar aurora is easily seen in the dusk sector of the polar cap. The proton intensification is seen at the nightside base of the transpolar arc at 0811 and 0813 UT in the SI12 images. The intensification also appears in the WIC counts, and it is essentially due to the contribution of the proton aurora to the WIC signal.

proton intensification at the nightside base of the transpolar arc developed around 0750 UT and lasted until about 0900 UT. Between 0810 and 0845 UT, it was particularly active, with a calculated proton flux $F_{p}$ higher than $1 \mathrm{~mW} / \mathrm{m}^{2}$ compared with $\sim 0.5 \mathrm{~mW} / \mathrm{m}^{2}$ and less on the rest of the oval. No comparable local intensification of the electron energy flux in the oval is observed. The brightening seen in the raw WIC image is due to the contribution of the proton aurora to the WIC signal. This contribution is determined using the SI12 measurements and removed before calculating the electron energy flux [Hubert et al., 2002]. The solar wind

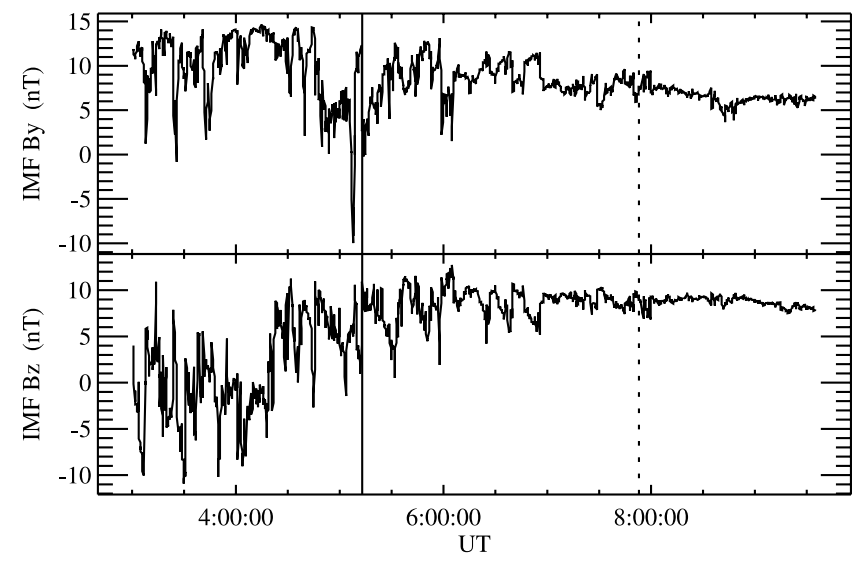

Figure 2. Solar wind conditions measured with the ACE satellite on 5 November 2000. (top) IMF $B_{y}$ (bottom) IMF $B_{z}$. The solid vertical line indicates the beginning of the transpolar event; the dotted vertical line corresponds to the spot appearance. The UT time axis has been corrected to account for the transport time delay between the satellite and the Earth. 

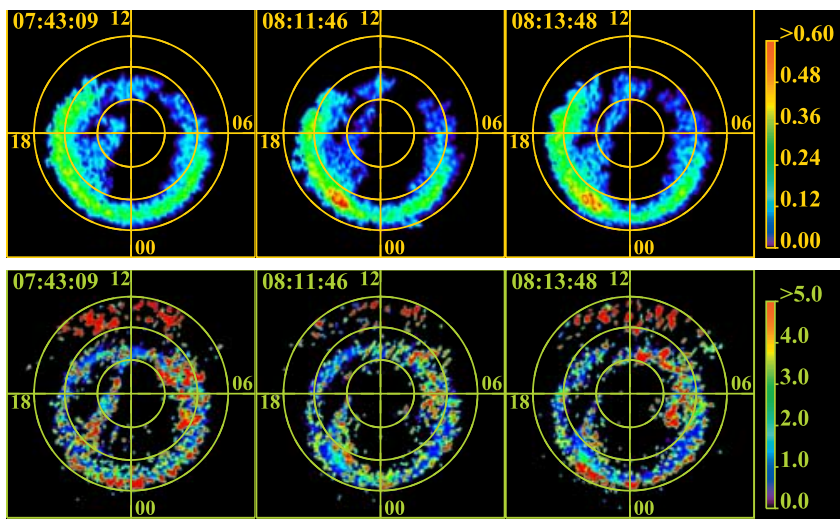

Figure 3. Calculated (top) proton and (bottom) electron energy fluxes associated with the counts showed in Figure 1, presented in geomagnetic coordinates (as in Figure 1). The energy fluxes are expressed in $\mathrm{mW} / \mathrm{m}^{2}$. The intensification at the base of the transpolar arc is seen in the proton flux at 0811 and 0813 UT, but it does not appear in the electron flux, because the contribution of the proton aurora was subtracted before calculating the electron energy flux.

properties measured by the ACE, Wind and Geotail satellites (not shown) did not show any specificity that could reveal the cause of the appearance of the bright proton spot at the base of the transpolar arc. The dynamic pressure measured by the GEOTAIL satellite was low, fluctuating around $\sim 3 \mathrm{nPa}$, the IMF components were stable: $B_{z} \sim 11.5 \mathrm{nT}, B_{y} \sim 3 \mathrm{nT}$ and $B_{x}$ $\sim-2 \mathrm{nT}$.

[12] On 8 November 2000, a faint transpolar arc was observed in the dusk sector, close to the noon-midnight meridian between 0235 and 0325 UT, when it faded down, and reappeared around 0349 UT in the dusk sector to sweep dawnward and nearly aligned on the noon-midnight meridian between 0530 and 0700 UT. The IMF $B_{z}$ component was strongly positive, while $B_{y}$ was weakly positive $(\sim 4 \mathrm{nT})$ (Figure 4), consistent with the duskside appearance of the arc. Its motion after 0349 UT is probably related to the negative $B_{y}$ component around 0400 UT (Figure 4). Between 0550 and $0610 \mathrm{UT}$, the proton auroral oval was slightly brighter at the base of the transpolar arc $\left(F_{p} \sim\right.$ $\left.0.7 \mathrm{~mW} / \mathrm{m}^{2}\right)$ than the rest of the oval $\left(F_{p} \sim 0.2 \mathrm{~mW} / \mathrm{m}^{2}\right.$ and lower), with no equivalent enhancement in the electron aurora. The arrival of two solar wind dynamic pressure pulses led to a brightening of the oval and to the appearance of a dayside subauroral proton flash at 0345 and 0614 UT [Hubert et al., 2003] unrelated to the transpolar structure itself.

\subsubsection{November 2000}

[13] A double transpolar aurora was detected with FUV between 1220 and 1830 UT, with one of the arcs in the dusk sector of the polar cap, and the other in the dawn sector very close to the noon-midnight meridian. Both arcs merged around 1320 UT along the noon-midnight meridian. The IMF $B_{z}$ component was mostly positive prior to the arc formation (Figure 5) as usual for transpolar arcs, while $B_{y}$ encountered a sign change slightly less than 2 hours before the arcs developed, and remained positive later. The dynamic pressure rose at the time of the arc formation due to an increase of both the solar wind density and velocity. During the transpolar event, $B_{z}$ was mostly posi-

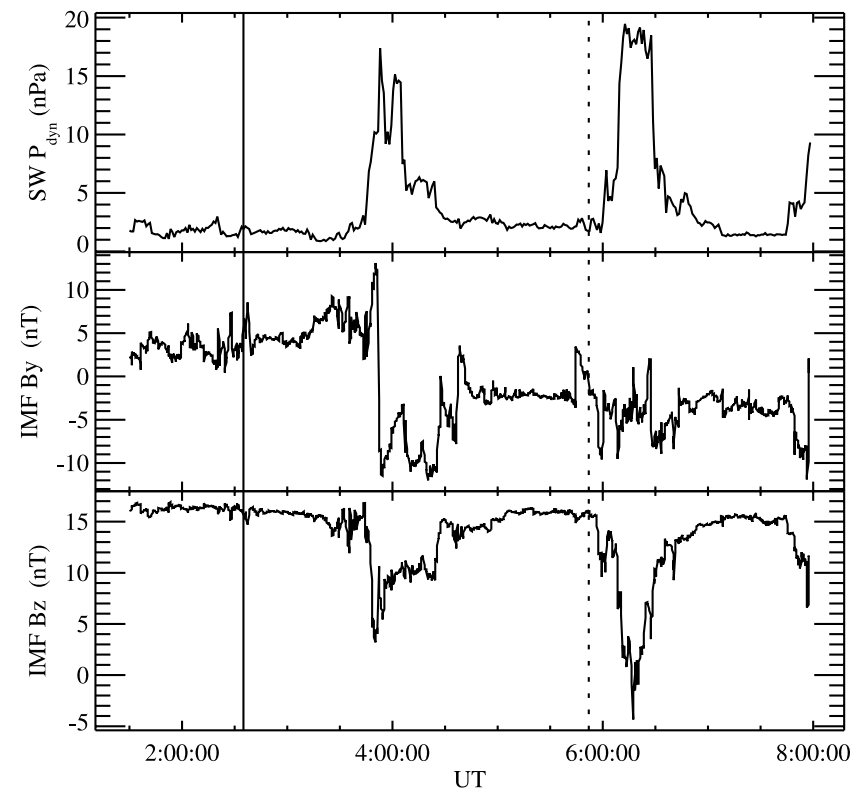

Figure 4. Solar wind conditions measured with the ACE satellite on 8 November 2000. (top) Solar wind dynamic pressure. (middle) IMF $B_{y}$. (bottom) IMF $B_{z}$. The solid vertical line reports the beginning of the transpolar event; the dotted vertical line corresponds to the spot appearance. The UT time axis has been corrected to account for the transport time delay between the satellite and the Earth.

tive with occasional negative excursions. From 1250 to 1312 UT, a spot of proton activity, well localized at the base of a transpolar arc was observed between $\sim 0000$ and $\sim 0100$ MLT. Two transpolar structures were present at that

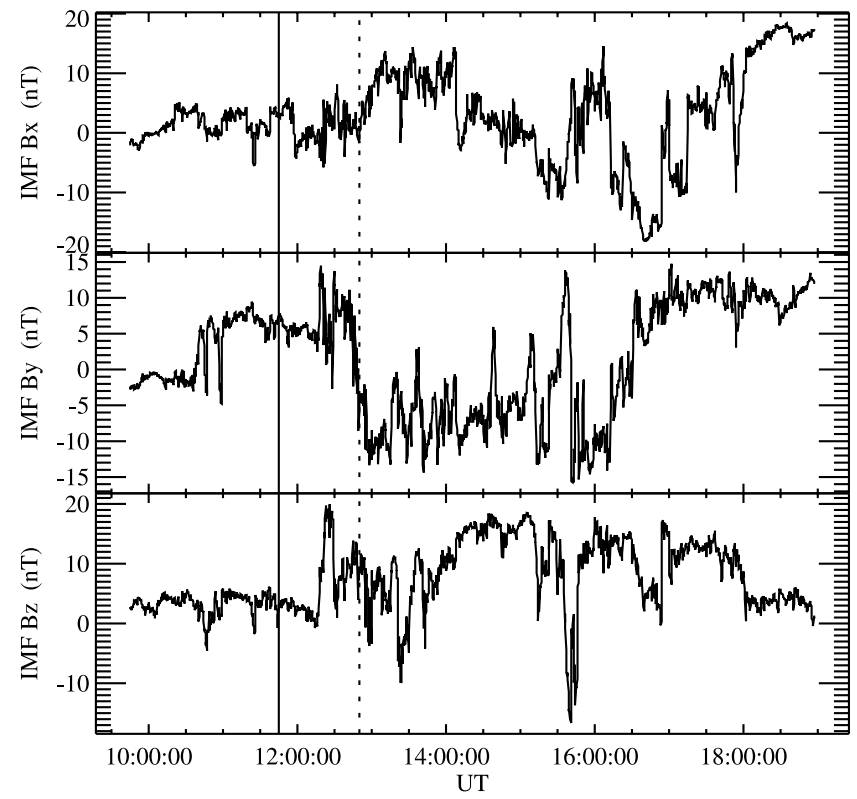

Figure 5. Solar wind conditions measured with the ACE satellite on 26 November 2000. (top) IMF $B_{x}$. (middle) IMF $B_{y}$. (bottom) IMF $B_{z}$. The solid vertical line indicates the beginning of the transpolar event; the dotted vertical line corresponds to the spot appearance. The UT time axis has been corrected to account for the transport time delay between the satellite and the Earth. 

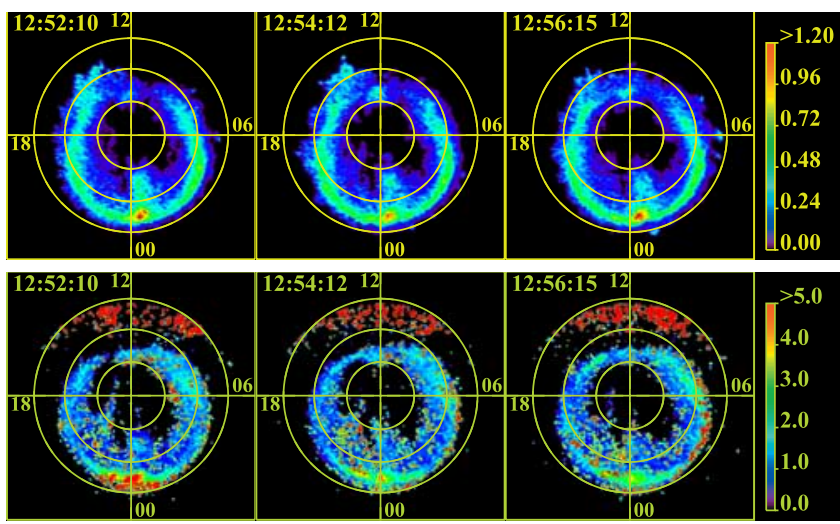

Figure 6. Calculated energy fluxes (color scales in $\mathrm{mW} / \mathrm{m}^{2}$ ) for the (top) protons and (bottom) electrons obtained at 1252, 1254 and 1256 UT on 26 November 2000. The images are presented in geomagnetic coordinates; the concentric circles are $10^{\circ}$ apart. Two transpolar structures are seen simultaneously, one in the dusk part of the polar cap, the other close to the noon-midnight line. A proton intensification of the auroral oval is seen at the base of the transpolar arc at $\sim 0030$ MLT.

time, but only one showed a proton spot at its base. Figure 6 shows the proton and electron energy fluxes calculated with three consecutive FUV snapshots. The proton flux in the spot deduced from the SI12 images was larger than $2 \mathrm{~mW} / \mathrm{m}^{2}$. A possible intensification of the electron flux is also deduced, wider than and nearly co-located with the proton spot. Both the IMF $B_{x}$ and $B_{y}$ components, as measured by the ACE satellite, changed sign around the time the spot appeared (Figure 5).

\subsubsection{November 2000}

[14] A transpolar arc developed at $\sim 0320$ UT around 2300 MLT and moved dawnward. About an hour before the transpolar arc formed, the IMF $B_{z}$ turned from negative to positive, while $B_{y}$ turned from positive to negative (Figure 7), consistently with the dawnward motion of the arc. The proton oval was bright between 0000 and 0600 MLT even before the appearance of the transpolar structure and brightened during the development of the transpolar emission. Around 0340 UT, the base of the transpolar arc was located in the active proton sector. No similar morphology was observed in the calculated electron auroral flux. Around $\sim 0355$ UT, the magnetosphere was disturbed by the arrival of a density pulse measured by the ACE and Wind satellites. Before the interplanetary shock, the solar wind dynamic pressure deduced from the Wind satellite measurements (Figure 7) was $\sim 5 \mathrm{nPa}, B_{x}$ and $B_{y}$ were both lower than $-10 \mathrm{nT}$, and $B_{z}$ was positive. The arrival of the shock first caused a localized brightening of the proton oval in the premidnight sector, i.e., not at the base of the transpolar arc, corresponding to the onset of the substorm, also observed in the electron energy flux. Both the electron and proton fluxes increased dramatically at the base of the transpolar arc around 0415, while the substorm triggered by the pressure pulse was developing.

3.1.3. 10 January 2001

[15] No brightening of the proton oval was seen in relation with the transpolar event detected between 2110 and 2315 UT. The transpolar arc observed during this period

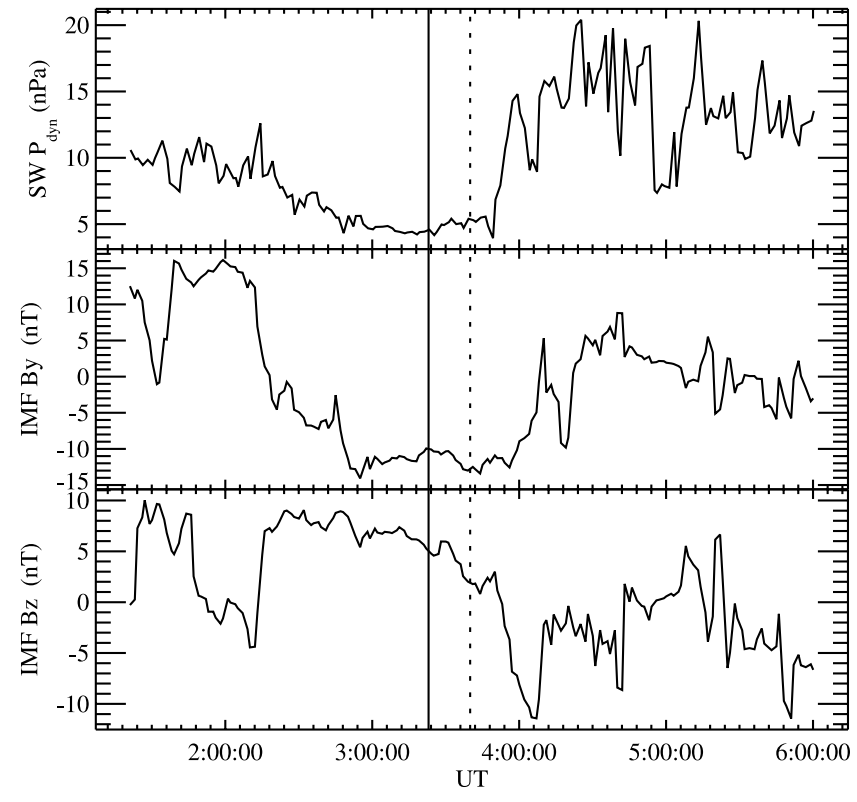

Figure 7. Solar wind conditions measured with the Wind satellite on 27 November 2000. (top) Solar wind dynamic pressure. (middle) IMF $B_{y}$. (bottom) IMF $B_{z}$. The solid vertical line indicates the beginning of the transpolar event; the dotted vertical line corresponds to the spot appearance. The UT time axis has been corrected to account for the transport time delay between the satellite and the Earth.

developed from the dawnside of the oval and migrated duskward. The formation of the transpolar arc at the dawn side of the oval is consistent with the negative $B_{y}$ observed with the ACE satellite before 2110 UT (Figure 8), and its duskward motion is consistent with the $B_{y}$ sign change at 2112 UT.

\subsubsection{November 2001}

[16] A transpolar arc was observed, developing on the dusk side (the very beginning of the event was not seen with

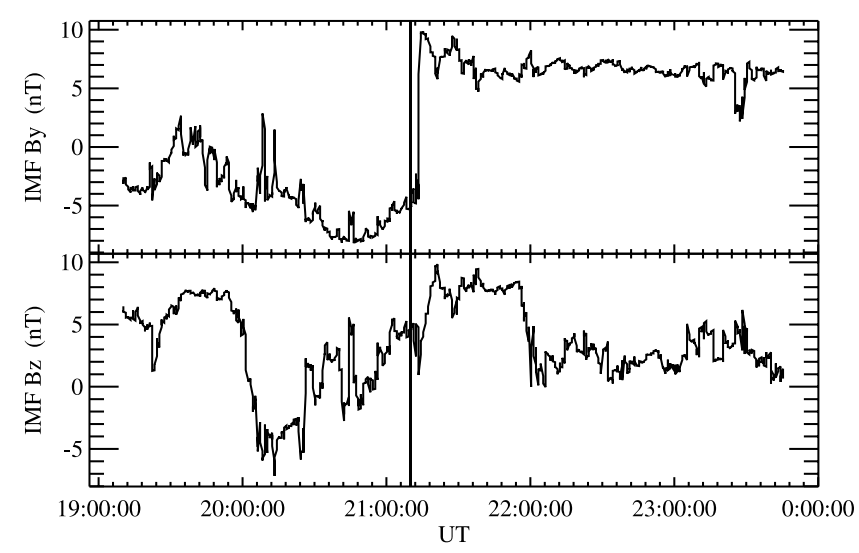

Figure 8. Solar wind conditions measured with the ACE satellite on 10 January 2001. (top) IMF $B_{y}$ (bottom) IMF $B_{z}$. The solid vertical line reports the beginning of the transpolar event, no proton spot was seen during this event at the base of the transpolar arc. The UT time axis has been corrected to account for the transport time delay between the satellite and the Earth. 

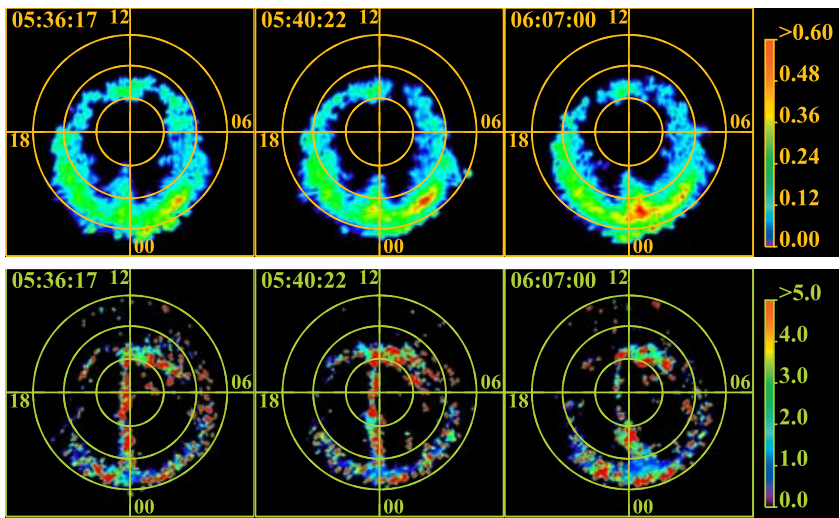

Figure 9. Calculated energy fluxes (color scales in $\mathrm{mW} / \mathrm{m}^{2}$ ) for the (top) protons and (bottom) electrons obtained at 05360540 and 0607 UT on 25 November 2001. The images are presented in geomagnetic coordinates; the concentric circles are $10^{\circ}$ apart. The localized intensification of the proton oval at the base of the transpolar cap coincides with the distortion of the arcs, which is apparent in the electron energy flux map at 0540 UT. At 0607 UT, the transpolar arc, as seen in the electron flux map, exhibits a distorted morphology, and the proton intensification has spread in MLT.

IMAGE-FUV) between 0030 and 0923 UT, with a brightness variable with time. The arc was aligned on the noonmidnight meridian between $\sim 0500$ and $\sim 0820$ UT. At 0538 UT, a distortion of the transpolar arc is observed: the nightside segment of the arc between $\sim 70^{\circ}$ and $\sim 80^{\circ}$ MLAT moved dawnward, while the rest of the arc moved duskward, progressively distorting the theta bar (Figure 9). Simultaneously, a proton spot developed at the base of the transpolar arc (flux $>1 \mathrm{~mW} / \mathrm{m}^{2}$ ) with an increasing extension. No similar structure was seen in the calculated electron flux: the larger WIC counts observed in this region are essentially due to the contribution of the proton aurora to the WIC signal. At that time, the solar wind dynamic pressure from the Geotail measurements was $<6 \mathrm{nPa}, B_{x}$ becoming close to 0 at the time of the spot appearance and turning positive again a few minutes later (Figure 10), while $B_{y}$ increased from $\sim 4 \mathrm{nT}$ to $\sim 8 \mathrm{nT}$. $B_{z}$ remained stable between $\sim 10$ and $\sim 15 \mathrm{nT}$ during several hours. The Wind (ACE) data (not shown) show a positive (negative, respectively) nearly 0 IMF $B_{x}$ component, but no sign change. The IMF $B_{z}$ and $B_{y}$ components measured with the Geotail satellite were positive before and during the transpolar arc event (Figure 10), with a few $B_{y}$ negative excursions if we also refer to the ACE and Wind satellites measurement (not shown). These IMF conditions are consistent with the observed location of the arc. Later, at $\sim 0740$ UT, the transpolar arc appears aligned again (i.e., no longer distorted). A spot of proton injection is seen again at the base of the transpolar arc at $\sim 2300$ MLT $\left(\mathrm{B}_{\mathrm{x}}, B_{y}\right.$ and $B_{z}$ were all positive). It progressively extends in MLT, mostly eastward, and persists after 0830 UT under the form of a zone of proton injection $\sim 3$ MLT hours wide (from $\sim 2300$ to $\sim 0200 \mathrm{MLT}$ ), while the base of the transpolar arc is located between 2300 and 0000 MLT. As the proton injection region expands along the oval, the transpolar structure widens on its night side, and at 0820 UT, it shows a distorted shape again.

\subsubsection{December 2001}

[17] The FUV images show a transpolar aurora detaching from the dawn side of the oval and slowly migrating duskward between $\sim 0315$ and $\sim 1200$ UT, with a nightside foot located between 0000 and 0200 MLT (hook-shaped during the first phase of the arc development, until it is aligned parallel to the noon-midnight meridian). The very beginning of the event is not seen. The negative IMF $B_{y}$ measured before 0315 UT and during the event (Figure 11) is consistent with the dawnside appearance of the arc, but no $B_{z}$ or $B_{y}$ sign change suggest a moving arc. However, the arc movement is very slow, and its nightside foot nearly does not move, so that its apparent motion could be interpreted as a slow process of formation of the arc detaching from the oval, consistently with the observed solar wind IMF. An intensification of the proton precipitation on the oval at the base of the transpolar arc is seen between 0425 and 0520 UT and between $\sim 0800$ and $\sim 1130$ UT with a variable brightness, and sporadic brightening between 0700 and 0800 UT. The proton energy flux is relatively intense (for an undisturbed period) at this location around $\sim 0920$ UT and $\sim 1115$ UT (more than $0.6 \mathrm{~mW} / \mathrm{m}^{2}$ in an extended area). No significant variation of the solar wind IMF characteristics can be identified in the ACE data (the Wind and Geotail positions were not favorable) as potentially responsible for the brightening at 0425: $B_{z}$ remained positive

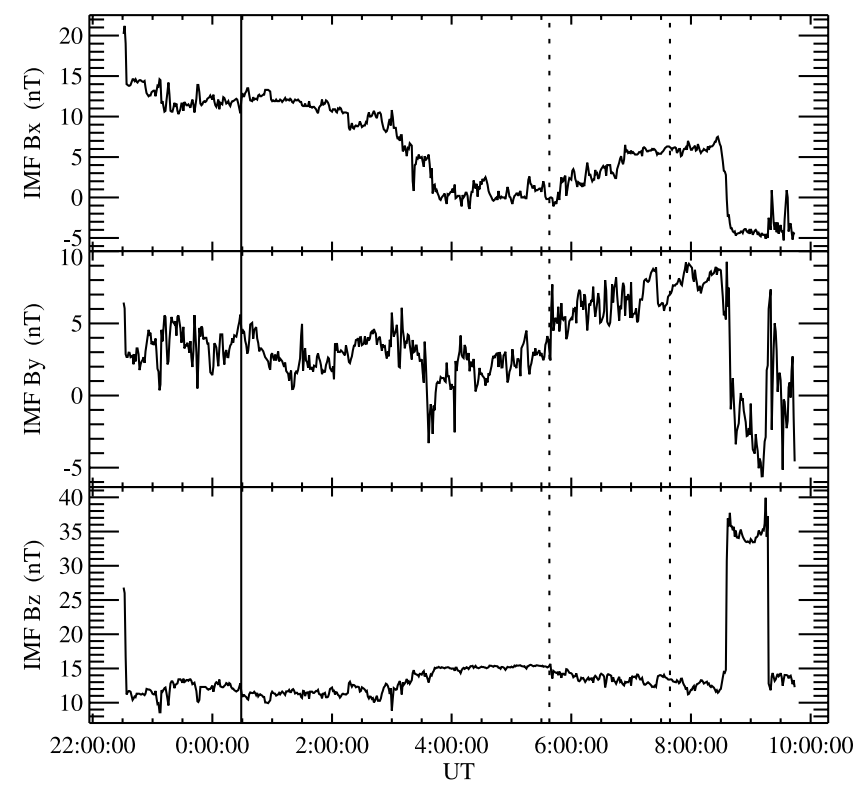

Figure 10. Solar wind conditions measured with the GEOTAIL satellite on 25 November 2001. (top) IMF $B_{x}$. (middle) IMF $B_{y}$ (bottom) IMF $B_{z}$. The solid vertical line indicates the beginning of the transpolar event, the dotted vertical line at 0538 UT corresponds to the beginning of the arc distortion and the simultaneous spot appearance. The dotted vertical line at 0740 UT corresponds to the appearance of the second proton spot observed during this transpolar event. The UT time axis has been corrected to account for the transport time delay between the satellite and the Earth. 


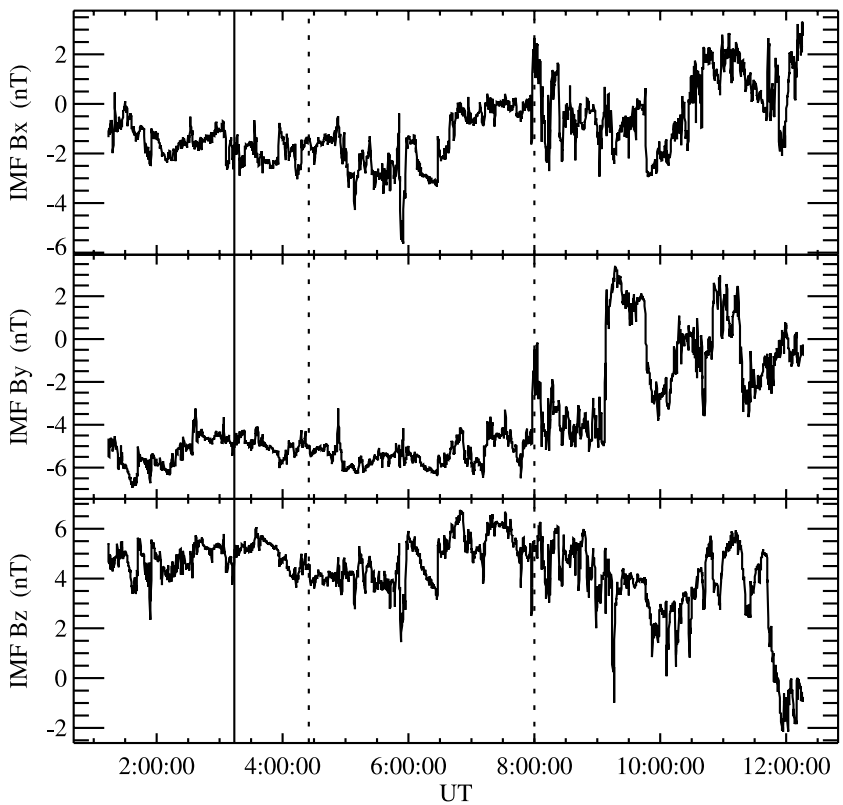

Figure 11. Solar wind conditions measured with the ACE satellite on 2 December 2001. (top) IMF $B_{x}$. (middle) IMF $B_{y}$. (bottom) IMF $B_{z}$. The solid vertical line indicates the beginning of the transpolar event; the dotted vertical lines correspond to the spot appearances. The UT time axis has been corrected to account for the transport time delay between the satellite and the Earth.

throughout the period, $B_{x}$ and $B_{y}$ were negative. $B_{y}$ was mostly negative and nearly 0 at 0800 UT (it was positive between $\sim 0910$ and $\sim 0940$ UT). $B_{x}$ changed sign when the spot appeared around 0800. The solar wind density (not shown) increased rather steadily from $\sim 8 \mathrm{~cm}^{-3}$ at $\sim 0620$ UT to $\sim 27 \mathrm{~cm}^{-3}$ at $\sim 1140$ UT, the dynamic pressure (not shown) presented the same evolution.

\subsubsection{December 2001}

[18] A stable transpolar aurora was observed in the duskside of the polar cap between $\sim 0830$ and 1015 UT. The IMF $B_{z}$ and $B_{y}$ conditions obtained with the ACE satellite prior to the arc development are shown in Figure 12. The $B_{z}$ component was positive, and $B_{y}$ was negative during the preceding $45 \mathrm{~min}$. These conditions usually correspond to a transpolar arc developing in the dawn side of the polar cap, in disagreement with the FUV observations. However, $B_{y}$ was positive before $0750 \mathrm{UT}$. To reconcile the IMF and FUV measurements, it can be speculated that the arc is actually a moving arc, but that the motion is too slow and the observing period too short to establish the motion. Throughout the event, the proton oval was bright between 1800 and 2400 MLT, with estimated energy fluxes larger than $2 \mathrm{~mW} / \mathrm{m}^{2}$, so that during the transpolar event, the proton injection was more intense at the base of the transpolar arc than in the rest of the oval, and the brighter zone started intensifying and expanding in MLT around 0915. At 1005 UT, a clear brightening is seen at the base of the transpolar arc, connected to the larger active zone of the oval reported above. After 1014 UT, the spacecraft is no longer in suitable location to observe the arc. No correlation can be established between the brightening and the solar wind properties measurements of the ACE, Wind and Geo-

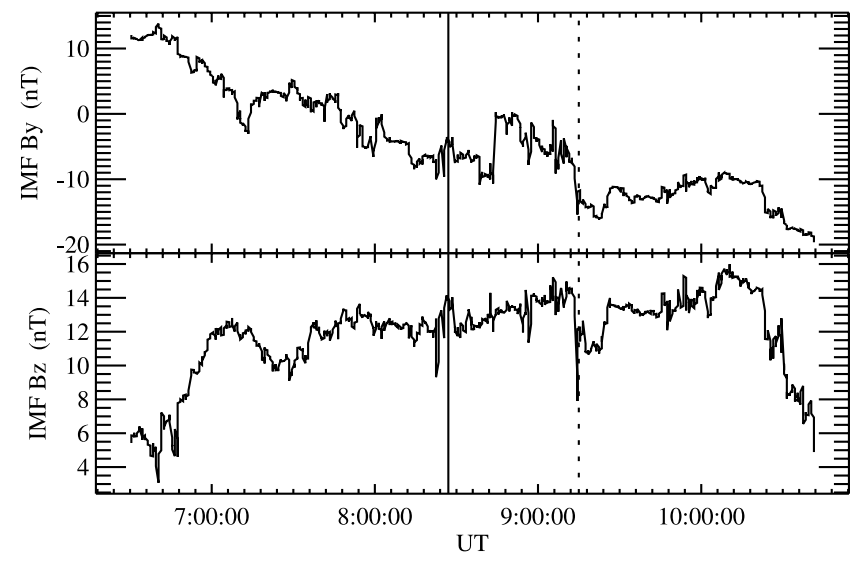

Figure 12. Solar wind conditions measured with the ACE satellite on 30 December 2001. (top) IMF $B_{y}$ (bottom) IMF $B_{z}$. The solid vertical line indicates the beginning of the transpolar event; the dotted vertical line corresponds to the spot appearance. The UT time axis has been corrected to account for the transport time delay between the satellite and the Earth.

tail satellites. In particular, none of the IMF components changed sign around the time of the spot appearance.

\subsubsection{January 2002}

[19] A transpolar arc developed in the dawn side of the polar cap between $\sim 0815$ and $\sim 1255$ UT. The arc remained rather stable in the dawn sector until $\sim 1000$ UT when it began migrating duskward. The development of the arc in the dawn sector is consistent with the negative IMF $B_{y}$ measured with the ACE satellite (Figure 13), while the

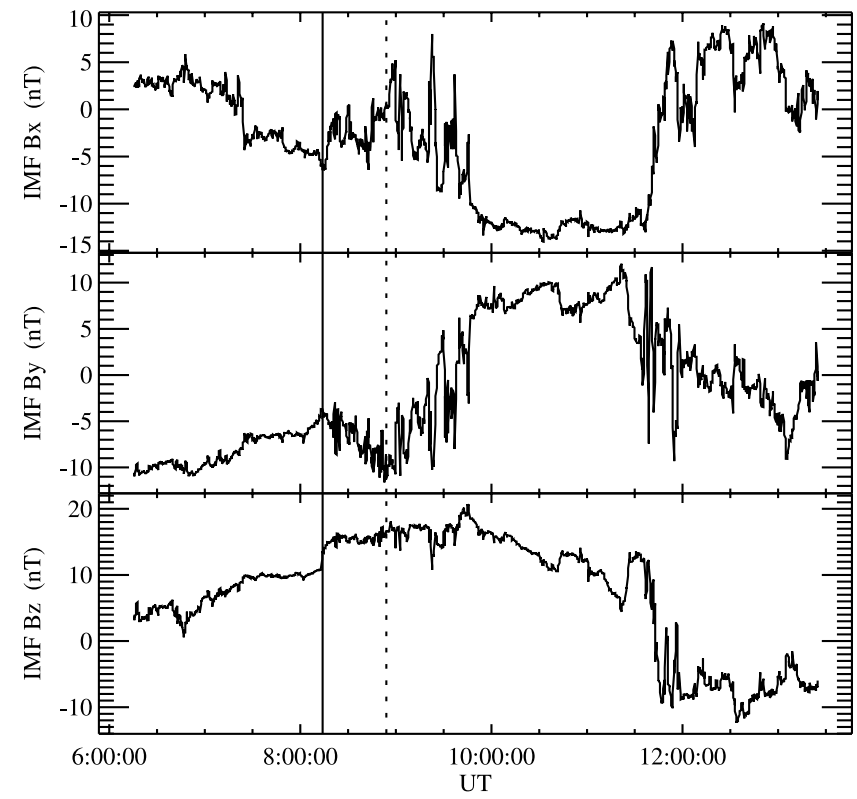

Figure 13. Solar wind conditions measured with the ACE satellite on 2 December 2001. (top) IMF $B_{x}$. (middle) IMF $B_{y}$. (bottom) IMF $B_{z}$. The solid vertical line indicates the beginning of the transpolar event; the dotted vertical line corresponds to the spot appearance. The UT time axis has been corrected to account for the transport time delay between the satellite and the Earth. 

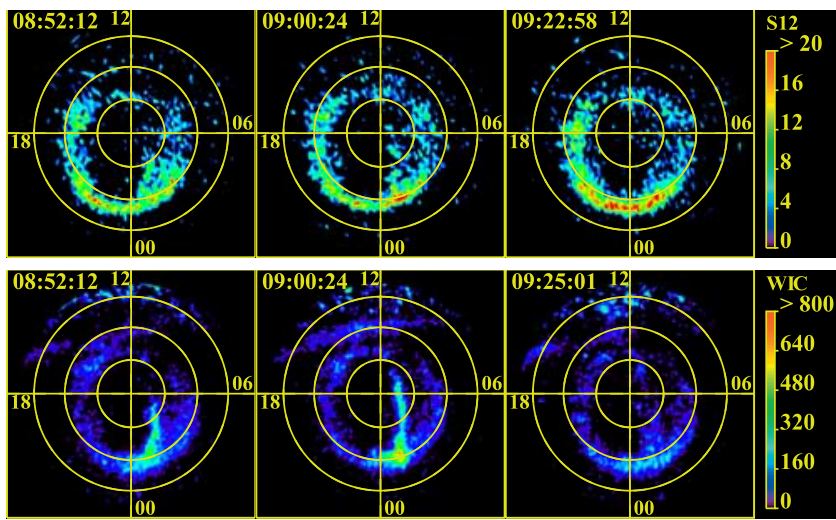

Figure 14. (top) SI12 and (bottom) WIC counts obtained on 19 January 2002, at three selected hours, in geomagnetic coordinates after background removal. At 0852 UT, the transpolar arc is seen, but no proton spot at the base of the transpolar arc. At 0900 UT, the spot is seen at the base of the transpolar arc in the SI12 instrument (proton aurora) and in the WIC signal. After removal of the proton contribution to the WIC counts to calculate the electron energy flux, an electron flux enhancement is seen in the electron flux as well. The electron spot vanishes rapidly while the proton intensification remains, as seen at 0925 UT.

migration of the arc beginning around 1000 UT seems related to the $B_{y}$ sign change detected around 0930 UT. $B_{z}$ was positive as usual during transpolar arc events. Around $\sim 0855$ UT, the foot of the transpolar arc, located post midnight on the proton oval, started to intensify. The intensification expanded eastward, finally covering a width of $\sim 5$ MLT hours at 0930 UT, as shown on Figure 14. Also, at 0900 UT (see Figure 14), the WIC signal presents an intensification that cannot be totally attributed to the proton precipitation, suggesting a weak electron contribution. This electron signature is only seen at 0900 UT. Until 0855 UT, the IMF $B_{x}$ component measured with the ACE satellite had been negative, but between $\sim 0850$ and 0900 UT, it started to oscillate and changed sign several times, while $B_{y}$ also suffered rapid variations without changing sign, and $B_{z}$ remained rather steady.

\subsubsection{February 2002, First Event}

[20] A transpolar structure was seen to develop from the premidnight sector between $\sim 0910$ and $\sim 1225$ UT, extending from the nightside oval a bit duskward from the noonmidnight meridian. It then moved duskward. Before the arc appeared, $B_{z}$ was weakly positive (between 0 and $8 \mathrm{nT}$ ), and $B_{y}$ was positive (Figure 15), with an excursion close to 0 around $0815 \mathrm{UT}$. It is tempting to relate the development of the arc from the nightside oval to this excursion, and the motion of the arc to the overall positive value of $\mathrm{B}_{\mathrm{y}}$. At 1031 UT, the SI12 images reveal the development of a proton spot in the auroral oval at the base of the transpolar arc between $\sim 2300$ and $\sim 0000$ MLT (see Figure 16). At 1033 UT, a localized emission spot is seen on a single image only in the electron aurora well co-located with the proton spot. Such a weak signature sporadically reappears later. Between 1031 and 1055 UT, the proton spot extends progressively into a wide bright zone of the oval extending from $\sim 2100$ to $\sim 0100$ MLT. For most of the time, the base

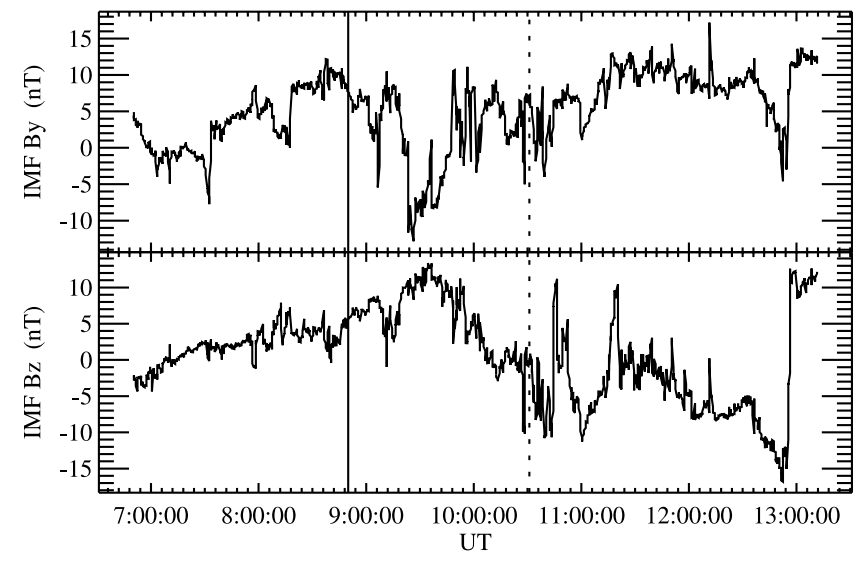

Figure 15. Solar wind conditions measured with the ACE satellite on 5 February 2002, between 0650 and 1310 UT (first transpolar event of the day). (top) IMF $B_{y}$. (bottom) IMF $B_{z}$. The solid vertical line indicates the beginning of the transpolar event; the dotted vertical line corresponds to the spot appearance. The UT time axis has been corrected to account for the transport time delay between the satellite and the Earth.

of the transpolar arc is located near the center of the active zone. The transpolar arc disappears by migrating to the dusk side of the oval, but the active proton zone keeps its original location as if it were no longer linked to the transpolar arc. The solar wind properties measured with the ACE satellite (Figure 15) show that, in the period of time around the appearance of the spot, the IMF $B_{z}$ component changed sign at least once, $B_{y}$ was positive and made a negative excursion roughly at the time the spot appeared. The other solar wind parameters did not show particular variations.

3.1.9. 5 February 2002, Second Event

[21] A transpolar structure was observed between 1400 and $1600 \mathrm{UT}$, stable in the dusk side of the polar cap. The
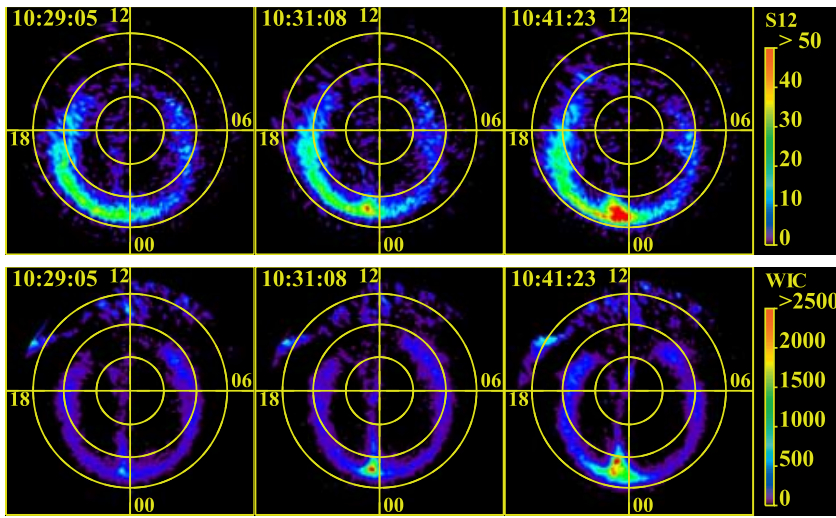

Figure 16. (top) SI12 and (bottom) WIC counts obtained on 5 February 2002, at three selected hours, in geomagnetic coordinates after background removal. These three consecutive snapshots show the birth of the proton spot at the base of the transpolar arc observed on 5 February 2002. In this case, the subtraction of the proton contribution from the WIC signal (not shown) reveals a sporadic weak and localized electron signature in the spot. The proton contribution nevertheless remains dominant. 


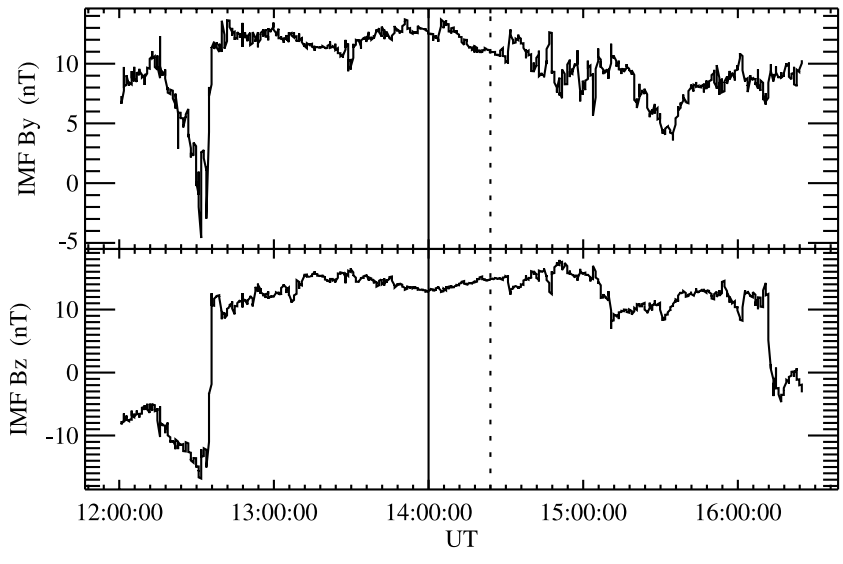

Figure 17. Solar wind conditions measured with the ACE satellite on 5 February 2002, between 1200 and 1625 UT (second transpolar event of the day). (top) IMF $B_{y}$. (bottom) IMF $B_{z}$. The solid vertical line indicates the beginning of the transpolar event, the dotted vertical line corresponds to the spot appearance. The UT time axis has been corrected to account for the transport time delay between the satellite and the Earth.

positive IMF $B_{z}$ and $B_{y}$ (Figure 17) of the ACE data during more than $80 \mathrm{~min}$ before the arc development are consistent with the stable development of the arc in the dusk side of the polar cap. Shortly after the transpolar structure appeared, the proton oval intensified in the premidnight sector with a maximal extension from $\sim 2000$ to $\sim 0000$ MLT, and a calculated energy flux larger than $2 \mathrm{~mW} / \mathrm{m}^{2}$. An intense activity persisted in that region after the transpolar arc disappeared. A discrepancy exists between the ACE and Wind solar wind data, probably due to the distant position of the Wind satellite with $\mathrm{Y}_{\mathrm{GSE}} \sim-318 R_{E}$. The ACE measurements show a $B_{z}$ component positive during the entire event. These data do not present any particular variation of the solar wind parameters. In particular, $B_{z}$ and $B_{y}$ both stay positive, $B_{x}$ negative.

\subsubsection{February 2002}

[22] The transpolar event observed with the FUV imagers between 1455 and 1730 UT developed from the dusk side of the oval and migrated dawnward after $\sim 1520$. Around 1545 UT, the arc distorted in a sort of S shape, it progressively lost its structure after 1615 UT, and had disappeared after 1730 UT. $B_{z}$ was positive during the 30 min preceding the transpolar arc formation, and $B_{y}$ was basically positive, in agreement with the development of the arc in the dusk sector (Figure 18). The negative $B_{y}$ after 1500 (with positive excursions) is probably associated with the dawnward migration of the arc. In addition, the disturbed nature of the IMF $B_{z}$ and $B_{y}$ after $1500 \mathrm{UT}$ is probably related with the distortion of the arc. An intensification of the nightside proton oval developed at 1636 UT slightly duskward of the base of the transpolar arc and extended both dawnward and duskward with time. Both the electron and proton nightside sections of the oval enlarged while the proton precipitation was increasing. Around the time of the development of the proton intensification, the GEOTAIL data showed that the IMF $B_{y}$ component changed sign, and that $B_{z}$ encountered two sign changes, first from negative to positive, and second from positive to negative. However, $B_{z}$ was positive at the beginning of the development of the transpolar arc.

\subsection{Comparison With Pseudobreakups}

[23] Since the appearance of the proton spot at the base of the transpolar arcs shows some resemblance with pseudobreakups, as was mentioned by Murphree et al. [1987], we compared the development of the observed spots with pseudobreakup. Pseudobreakups observed with IMAGEFUV on 6 October 2000, at 0331 UT (duration $\sim 12 \mathrm{~min}$ ), 5 January 2001, at 2143 UT (duration $\sim 8 \mathrm{~min}$ ) and at 2203 UT (duration $\sim 10 \mathrm{~min}$ ), 10 January 2001, at 0656 UT (duration $\sim 18 \mathrm{~min}$ ) and at $0719 \mathrm{UT}$ (duration $\sim 16 \mathrm{~min}$ ) were analyzed (not shown). Their average duration is $\sim 13 \mathrm{~min}$. For all events, the increase in precipitating flux was found to be simultaneous in both proton and electron precipitations, with a strong electron dominance, and with relative contributions of both particles to the total energy flux comparable to that found in substorms. On 6 October, 2000 and 10 January 2001, the solar wind IMF $B_{z}$ component measured with the ACE and Geotail (and Wind on 6 October 2000) satellites were positive during more than 2 hours prior to the pseudobreakup and during the pseudobreakup itself. Consequently, for these two events, the IMF conditions present similarities with the conditions usually met during transpolar events. Nevertheless, these two events do not present more similarity than the others with the observed spots. We conclude that pseudobreakups and the spots at the nightside base of theta auroras have not similar characteristics. It thus appears that these two phenomena are different, despite their similar localized morphology. The observed spots are thus not some kind of non-triggered substorms.

\subsection{Discussion}

[24] From a general standpoint, the dynamics of transpolar aurora events and related solar wind properties reported in this study are consistent with previous work by Kullen et al. [2002], Chang et al. [1998], Cumnock et al. [2002] and

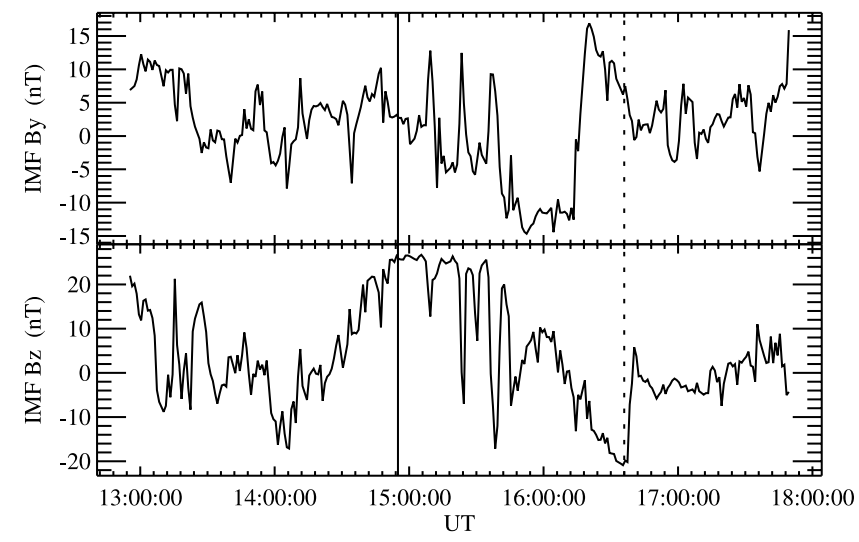

Figure 18. Solar wind conditions measured with the GEOTAIL satellite on 11 February 2002. (top) IMF $B_{y}$. (bottom) IMF $B_{z}$. The solid vertical line indicates the beginning of the transpolar event; the dotted vertical line corresponds to the spot appearance. The UT time axis has been corrected to account for the transport time delay between the satellite and the Earth. 
others. We find that transpolar arcs develop during long periods of predominantly northward IMF, and that the location of the transpolar arc and its motion is determined by the IMF $B_{y}$ component. $B_{y}$ sign changes occurring as early as one hour before the arc development can control the arc motion, as shown by several authors [Kullen et al., 2002; Cumnock et al., 2002].

[25] Table 1 summarizes the results obtained for each of the 12 transpolar auroras analyzed in this study concerning the proton spots. Eleven events showed an intensification of the proton precipitation, located at the base of the transpolar arc on the nightside (except for 27 November 2000). Two of these eleven events ( 8 November and 27 November 2000) were complicated by the arrival of an interplanetary shock, and one case did not show any brightening at the base of the transpolar arc (10 January 2001). A nightside proton spot was thus observed in $92 \%$ of the cases presented in this work. The observed intensifications are generally fairly well centered on the axis of the transpolar arc, and have a typical extension on the order of $0.5-1$ MLT hour, but cases of more extended intensifications were also observed. It appears that the intensification of the precipitation near the foot of the transpolar arc mostly affects the proton auroral flux, although an electron contribution to the brightening cannot be totally ruled out. It must be noted that the total precipitating energy flux (electrons plus protons) is still dominated by the electron component in the spot brightening, as it is in the whole oval. Using the model of Tsyganenko [1995], the field lines originating from the spot mapped to the equatorial plane at geocentric distances of $\sim 5$ to $\sim 8 R_{E}$, i.e., at distances somewhat larger than the ring current. These values are typical of the auroral oval, but it is not guaranteed that the Tsyganenko field line model remains appropriate in a period of transpolar aurora. Kullen [2000] and Kullen and Janhunen [2003] showed that transpolar arcs involve large-scale magnetotail changes. Moreover, even during periods without transpolar arc, mapping a field line to the tail is difficult because small differences in latitude translate to large distances downtail.

[26] We find that the extension of the intensified region is variable, in agreement with Murphree et al. [1987]. Our study indicates that the spot formation as rather frequent when a transpolar arc is observed (more than $90 \%$ of the presented cases show such a spot), with a variably long lifetime of several tens of minutes, mostly due to an increase of the proton precipitation. Murphree et al. [1987] noted the morphological resemblance between the spot and pseudobreakups. They also raised the question of a possible link between theta auroras and substorm. Our data set does not establish any link between pseudobreakups and the observed spots. Comparison of the spots and pseudobreakups shows that these two phenomena have different timescales and quantitative aspects: The spot intensification takes place nearly exclusively in the proton precipitation and lasts several tens of minutes, whereas pseudobreakups are characterized by an increase of both the electron and proton fluxes and last $\sim 10-15 \mathrm{~min}$. This could indicate that the mechanisms responsible for the particle injection are at least partly different for these two phenomena.

[27] The mechanism responsible for the observed proton spots is unclear. The results of the relation between the spot appearance and the IMF variations are summarized in
Table 1 (on 25 November 2001, $B_{y}$ was small and a distortion of the transpolar arc took place). An explanation based on IMF $B_{x}, B_{y}$, or $B_{z}$ reversals (or near nullification) would not account for the three cases observed for which no IMF "singularity" was found. As no correlation is found between the IMF components and the development of the observed spots, it is difficult to establish a causal link between IMF components sign reversals and the appearance of the spot, although the development of the arc itself is consistent with the observed IMF conditions. It must also be stressed that the correspondence between the solar wind conditions and the auroral phenomenon was analyzed on the basis of a transport of the solar wind material up to the planet, whereas it might be necessary to account for an additional time delay necessary for the solar plasma to move downtail, for transpolar aurora are related with the tail topology.

[28] Other temporal variations than IMF component sign changes may be important. We performed a basic wavelet transform analysis of the solar wind data, which revealed inconclusive. Moreover, for the 25 November 2001 case, the appearance of the distortion of the arc reveals temporal variations of the magnetospheric field structure, although the solar wind properties do not show important temporal variations (the reported $B_{x}$ oscillation has a much shorter timescale), suggesting a mechanism with a long timescale. One could speculate that a time variation of the magnetic field is more likely to divert the trajectory of the protons than of the electrons, and create a proton spot. Since the protons have a larger cyclotron radius and a longer cyclotron period than the electrons, they are more sensitive to temporal variations of the magnetic field: under these circumstances, the proton movement does not perfectly follow the guiding center approximation. Moreover, any acceptable mechanism should be able to explain why the intensification takes place at a given time and does not necessarily last during the whole transpolar event.

\section{Proton Contribution to the Transpolar Arc} 4.1. Observations

[29] The transpolar event of 27 November 2000 was disturbed by the arrival of an interplanetary shock on the front of the magnetosphere. As a consequence, the transpolar arc strongly intensified, and it was possible to derive quantitative information on the relative contribution of the protons in the transpolar structure on a global scale. Figure 19 shows the calculated electron and proton energy fluxes integrated over the complete oval, and the relative contribution of the protons to the total. Figure 20 shows the calculated proton and electron energy fluxes integrated over the transpolar arc only, and the relative contribution of the protons. The transpolar arc was hook-shaped, and the hook section parallel to the auroral oval was considered as belonging to the transpolar structure and included in the transpolar power calculation. It appears that, during this event, the transpolar structure contributed $8.4 \%$ of the total hemispheric power on the average $(8.6 \%$ for the electron precipitation, $6.3 \%$ for the protons, on the average). The relative contribution of the protons to the energy flux in the transpolar structure is $\sim 7.1 \%$ on average, a value comparable to the proton contribution in the main oval during the active period, i.e., $\sim 10 \%$. 


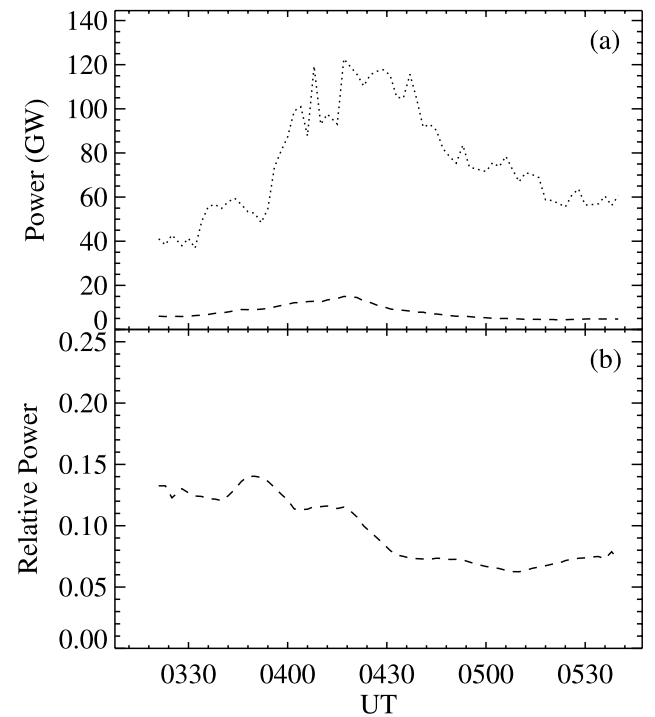

Figure 19. (a) Global hemispheric power for the event of 27 November 2000, for the electrons (dotted line) and the protons (dashed line). The effect of the arrival of the CME is apparent around 0355 UT. (b) Relative contribution of the protons to the total hemispheric power.

[30] The first event of 5 February 2002, between $\sim 0900$ and $\sim 1225$ UT, was also bright enough to carry a detailed analysis. The total hemispheric power and the transpolar arc power are presented in Figures 21 and 22, respectively. On average, the transpolar arc contributes $\sim 12 \%$ of the total hemispheric power, with a maximum value of $\sim 30 \%$ at 0955 UT, intermediate values of $\sim 17 \%$ at $1050 \mathrm{UT}$, and minimal values of $\sim 7 \%$ around 1205 UT. The calculated proton contribution to the hemispheric energy injection ranges between $20 \%$ and $5 \%$, with typical values of $\sim 8 \%$

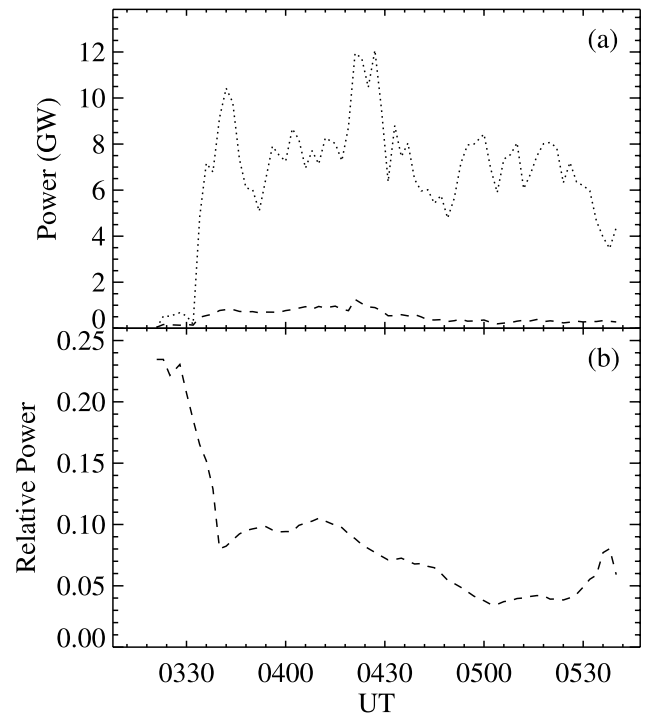

Figure 20. Precipitated power in the transpolar structure observed on 27 November 2000 (same lines as in Figure 19). A comparison of Figures 19 and 20 reveals that the transpolar structure contributes $\sim 8.5 \%$ to the total hemispheric power. The proton contribution varies between $\sim 5$ and $\sim 25 \%$ of the total power of the transpolar structure ( $\sim 7 \%$ on the average).

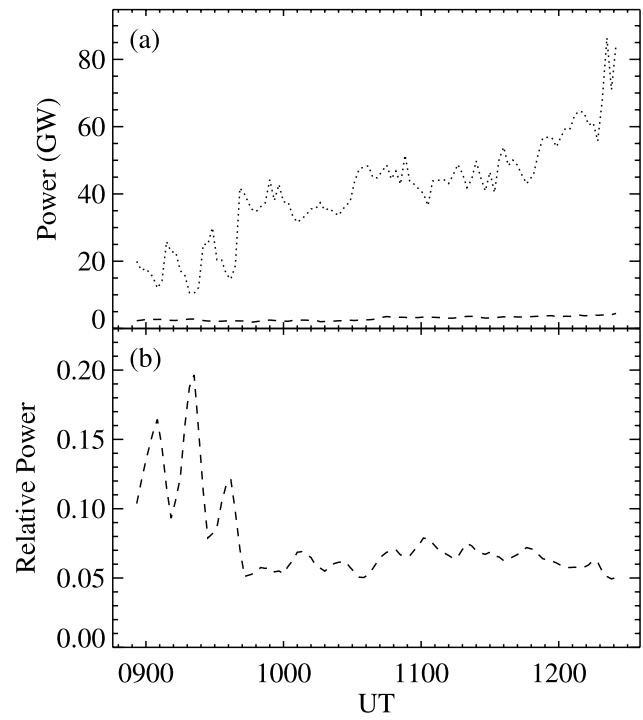

Figure 21. (a) Global hemispheric power for the first event of 5 February 2002 (same lines as in Figure 19). (b) Relative contribution of the protons to the total hemispheric power.

(Figure 21). This fraction is weaker in the transpolar arc, with typical values lower than $5 \%$ (3.1\% on average), although a maximum value of $\sim 20 \%$ is calculated at the beginning of the event. Around 1030 UT, the energy flux injected by the protons into the transpolar arc suddenly weakens. This is the time when the spot appears on the oval at the base of the transpolar arc.

\subsection{Discussion}

[31] We first focus on the brighter event of the list (27 November 2000). It presents a first phase where the

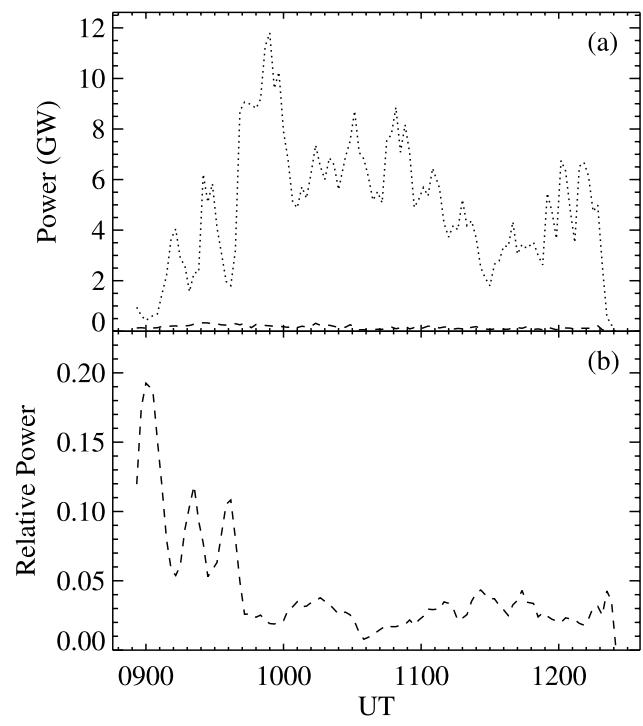

Figure 22. Precipitated power in the transpolar structure observed on 5 February 2002 (first event) (same lines as in Figure 19). A comparison of Figures 21 and 22 reveals that the transpolar structure contributes $\sim 12 \%$ of the total hemispheric power. In this case, the protons contribution varies between $\sim 1$ and $\sim 20 \%$ of the total power of the transpolar structure, $(\sim 3.1 \%$ on the average). 
activity was moderate, and a second phase characterized by the arrival of an interplanetary shock. During both phases, the calculated proton relative contribution to the energy flux decreases in both the transpolar arc and the main oval, remaining lower in the transpolar arc ( $\sim 7.1 \%$ on average) than in the auroral oval $(\sim 10 \%$ on average). The transpolar aurora is found to contribute $\sim 8.4 \%$ of the total hemispheric power on average.

[32] In the second event presented in this section (5 February 2002, morning), the transpolar arc has a flux comparable to the 27 November 2000 case in absolute value, but as the oval is more active on 27 November 2000 , the relative contribution of the transpolar arc to the total hemispheric power is larger on 5 February 2002 (first event of the day). On 5 February 2002, the transpolar arc contributed $\sim 12 \%$ of the total auroral precipitation. The relative contribution of the protons to the transpolar arc energy injection was $\sim 3.1 \%$. These values are fairly comparable to the 27 November 2000 values, although from a relative point of view, the protons contributed twice more to the transpolar arc on that day. The 5 February 2002 case (first event of the day) however presents an interesting feature: the proton energy flux injected in the transpolar arc decreases when the spot appears. This may indicate that at least a part of the protons injected in the spot comes from the same reservoir as the protons precipitating in the main structure of the transpolar arc (i.e., the part inside the polar cap). This could mean that the magnetosphere acquires a topology or a temporal dynamic that diverts the protons from the field lines mapping to the main structure of the transpolar arc to those mapping to the spot, i.e., at the junction between the transpolar arc and the oval. This would thus also imply a drastic violation of the first adiabatic invariant, giving a constraint to a potential injection mechanism. Such a depletion of the transpolar arc proton injection was not observed on 27 November 2000, but this case is unusual since it is disturbed by an IP shock and because the nightside proton oval was already active before the transpolar arc appeared.

\section{Summary}

[33] Twelve transpolar arc events observed with IMAGEFUV have been presented. Most of them presented an intensification of the auroral oval at the base of the transpolar arc. It appears that this intensification is dominated by proton injection, and that the properties of this spot-like injection differentiate them from pseudobreakups. No clear systematic link with the solar wind properties was found. In addition, the interaction with the solar wind can occur on the far nightside magnetosphere, making it very hard to establish at what time the solar wind data of interest were acquired by the ACE, Wind, or Geotail satellites. An explanation based on temporal variations of the IMF $B_{z}$ and/or $B_{y}$ and/or $B_{x}$ components would not account for all the observations. Moreover, no IMF component seems to play a predominant role. We thus suggest that this phenomenon is linked to a long-term response of the magnetosphere that integrates the solar wind influence over a yet undetermined period of time. Also, in the absence of relation of the observed spots and pseudobreakups, the spot at the base of transpolar arcs cannot be considered as some kind of nontriggered substorm like event.

[34] The relative contribution of the transpolar arc to the hemispheric power has been analyzed for two cases and found to be on the order of $\sim 10 \%$ to the total, on the average. Inside the studied transpolar arcs, the protons contribute $\sim 5 \%$ of the energy input of the transpolar arc. The depletion of the proton energy flux in the transpolar arc at the time the spot appears on 5 February 2000, at 1030 UT, may indicate that the protons injected in the spot were actually diverted from the field lines mapping to the transpolar arc.

[35] Acknowledgments. Jean-Claude Gérard and Benoît Hubert are supported by the Belgian National Fund for Scientific Research (FNRS). This work was funded by the PRODEX program of the European Space Agency (ESA) and the Fund for Collective and Fundamental Research (FRFC grants 97-2.4569.97 and 01-2.4569.01). Research at Lockheed Martin was supported by the IMAGE data analysis program through subcontract from the University of California, Berkeley. The IMAGEFUV investigation was supported by NASA through SWRI subcontract number 83820 at the University of California, Berkeley, contract NAS596020. ACE level 2 data were provided by N. F. Ness (MFI) and D. J. McComas (SWEPAM), and the ACE Science Center. GEOTAIL data (L. Frank, U. Iowa) and Wind data (R. Lepping, NASA/GSFC) were obtained through the CDA web site.

[36] Arthur D. Richmond thanks Judy A. Cumnock and A. Kullen for their assistance in evaluating this paper.

\section{References}

Akasofu, S.-I. (1964), The development of auroral substorm, Planet. Space Sci., 12, 273.

Burch, J. L. (2000), IMAGE Mission overview, Space Sci. Rev., 91, 1.

Burch, J. L., et al. (2001), Views of Earth's magnetosphere with the IMAGE satellite, Science, 291, 619.

Chang, S.-W., et al. (1998), A comparison of model for the theta aurora with observations from Polar, Wind, and SuperDARN, J. Geophys. Res., $103,17,367$.

Coumans, V., J. C. Gérard, B. Hubert, and D. S. Evans (2002), Electron and proton excitation of the FUV aurora: Simultaneous IMAGE and NOAA observations, J. Geophys. Res., 107(A11), 1347, doi:10.1029/ 2001JA009233.

Cumnock, J. A., J. R. Sharber, R. A. Heelis, M. R. Hairston, and J. D. Craven (1997), Evolution of the global aurora during positive IMF Bz and varying IMF $B_{y}$ conditions, J. Geophys. Res., 102, 17,489.

Cumnock, J. A., J. F. Spann, G. A. Germany, L. G. Blomberg, W. R. Coley, C. R. Clauer, and M. J. Brittnacher (2000), POLAR UVI observations of auroral oval intensifications during a transpolar arc event on December 7, 1996, Rep. TRITA-ALP-2000-1, R. Inst. of Technol., Stockholm.

Cumnock, J. A., J. R. Sharber, R. A. Heelis, L. G. Blomberg, G. A Germany, J. F. Spann, and W. R. Coley (2002), Interplanetary magnetic field control of theta aurora development, J. Geophys. Res., 107(A7), 1108, doi:10.1029/2001JA009126.

Frank, L. A., and J. D. Craven (1988), Imaging results from Dynamics Explorer 1, Rev. Geophys., 26, 249.

Frank, L. A., J. D. Craven, J. L. Burch, and J. D. Winningham (1982), Polar view of the Earth's aurora with Dynamics Explorer, Geophys. Res. Lett., 9, 1001 .

Frank, L. A., et al. (1986), The theta aurora, J. Geophys. Res., 91, 3177. Hardy, D. A., M. S. Gussenhoven, and D. Brautigam (1989), A statistical model of auroral ion precipitation, J. Geophys. Res., 94, 370.

Hardy, D. A., W. McNeil, M. S. Gussenhoven, and D. Brautigam (1991), A statistical model of auroral ion precipitation: 2. Functional representation of the average patterns, J. Geophys. Res., 96, 5539.

Hubert, B., J. C. Gérard, D. S. Evans, M. Meurant, S. B. Mende, H. U. Frey, and T. J. Immel (2002), Total electron and proton energy input during auroral substorms: Remote sensing with IMAGE-FUV, J. Geophys. Res., 107(A8), 1183, doi:10.1029/2001JA009229.

Hubert, B., J. C. Gérard, S. A. Fuselier, and S. B. Mende (2003), Observation of dayside subauroral proton flashes with the IMAGE-FUV imagers, Geophys. Res. Lett., 30(3), 1145, doi:10.1029/2002GL016464.

Koskinen, H. E. J., R. E. Lopez, R. J. Pellinen, T. I. Pulkkinen, D. N. Baker, and T. Bösinger (1993), Pseudobreakups and substorm growth phase in the ionosphere and magnetosphere, J. Geophys. Res., 98, 5801.

Kullen, A. (2000), The connection between transpolar arcs and magnetotail rotation, Geophys. Res. Lett., 27, 73. 
Kullen, A., and P. Janhunen (2003), Relation of polar auroral arcs to magnetotail twisting and IMF rotation: A systematic MHD simulation study, Ann. Geophys., 22, 951.

Kullen, A., M. Brittnacher, J. A. Cumnock, and L. G. Blomberg (2002), Solar wind dependence of the occurrence and motion of polar auroral arcs: A statistical study, J. Geophys. Res., 107(A11), 1362, doi:10.1029/ 2002JA009245.

Makita, K., C.-I. Meng, and S. I. Akasofu (1991), Transpolar auroras, their particle precipitation, and IMF $B_{y}$ component, J. Geophys. Res., 96, 14,085

Mende, S. B., et al. (2000a), Far ultraviolet imaging from the IMAGE spacecraft: 1. System design, Space Sci. Rev., 91, 243.

Mende, S. B., et al. (2000b), Far ultraviolet imaging from the IMAGE spacecraft: 3. Spectral imaging of Lyman alpha and OI $135.6 \mathrm{~nm}$, Space Sci. Rev., 91, 287.

Meng, C.-I., and B. H. Mauk (1991), Global auroral morphology, U.S. Natl. Rep. Int. Union Geod. Geophys. 1987-1990, Rev. Geophys., 29, 1028.

Menietti, J. D., and J. L. Burch (1987), DE 1 observations of theta aurora plasma source regions and Birkeland current charge carriers, J. Geophys. Res., 92, 7505.

Meurant, M., J. C. Gérard, B. Hubert, V. I. Shematovich, D. V. Bisikalo, D. S. Evans, G. R. Gladstone, and S. B. Mende (2003), Characterization and dynamics of the auroral electron precipitation during substorms deduced from IMAGE-FUV, J. Geophys. Res., 108(A6), 1247, doi:10.1029/2002JA009685.

Murphree, J. S., L. L. Cogger, C. D. Anger, D. D. Wallis, and G. G. Shepherd (1987), Oval intensifications associated with polar arcs, Geophys. Res. Lett., 14, 403.

Newell, P. T., D. Xu, C. I. Meng, and M. G. Kivelson (1997), Dynamical polar cap: A unifying approach, J. Geophys. Res., 102, 127.
Peterson, W. K., and E. G. Shelley (1984), Origin of the plasma in a crosspolar cap auroral feature (theta aurora), J. Geophys. Res., 89, 6729-6736. Sergeev, V. A., A. G. Yahnin, R. A. Rakhmatulin, S. I. Solovjev, F. S. Mozer, D. J. Williams, and C. T. Russell (1986), Permanent flare activity in the auroral zone, Planet. Space Sci., 34, 1169.

Slinker, S. P., J. A. Fedder, D. J. McFadden, Y. Zhang, and J. G. Lyons (2001), Polar cap study during northward interplanetary magnetic field on 19 January 1998, Phys. Plasmas, 8, 1119.

Tsyganenko, N. A. (1995), Modeling the Earth's magnetospheric magnetic field confined within a realistic magnetopause, J. Geophys. Res., 100, 5599.

Valladares, C. E., H. C. Carlson Jr., and K. Fukui (1994), Interplanetary magnetic field dependency of stable Sun-aligned polar cap arcs, J. Geophys. Res., 99, 6247.

Zhu, L., R. W. Schunk, and J. J. Sojka (1997), Polar cap arcs: A review, J. Atmos. Sol. Terr. Phys., 59, 1087.

J. L. Burch, Southwest Research Institute, 6220 Culebra Road, P. O. Drawer 28510, San Antonio, TX 78228-0510, USA.

S. A. Fuselier, Space Physics Laboratory, Lockheed Martin Advanced Technology Center, 3251 Hanover Street, O/L9-42, Building 255, Palo Alto, CA 94304-1191, USA.

J. C. Gérard and B. Hubert, Laboratoire de Physique Atmosphérique et Planétaire, Institut d'Astrophysique et de Géophysique, Université de Liège, Allée du 6 Août, 17, Bât B5c, Lìege B-4000, Belgium. (benoit@astro.ulg.ac.be)

S. B. Mende, Space Sciences Laboratory, University of California, Centennial Drive at Grizzly Peak Boulevard, Berkeley, CA 94720-7450, USA. 